[3] Gladman DD, Kavanaugh A, Gómez-Reino JJ, et al. Therapeutic benefit of apremilast on enthesitis and dactylitis in patients with psoriatic arthritis: a pooled analysis of the PALACE 1-3 studies. RMD Open. 2018;4(1):e000669.

[4] Wells AF, Edwards CJ, Kivitz AJ, et al. Apremilast monotherapy in DMARD-naive psoriatic arthritis patients: results of the randomized, placebo-controlled PALACE 4 trial. Rheumatology (Oxford) 2018;57:1253-63.

Disclosure of Interests: None declared.

DOI: 10.1136/annrheumdis-2021-eular.1850

\section{AB0546 5 YEARS FOLLOW-UP OF PSORIATIC ARTHRITIS PATIENTS TREATED ACCORDING TREAT-TO-TARGET STRATEGY. PRELIMINARY RESULTS}

P. Tremaskina ${ }^{1}$, E. Loginova ${ }^{1}$, T. Korotaeva ${ }^{1}$, S. Glukhova ${ }^{2}$, A. Lila ${ }^{1,3}{ }^{1}{ }^{1}$ V. A. Nasonova Research Institute of Rheumatology, Spondyloarthritis and psoriatic arthritis, Moscow, Russian Federation; ${ }^{2}$ V. A. Nasonova Research Institute of Rheumatology, medical and social problems in rheumatology, Moscow, Russian Federation; ${ }^{3}$ Medical Academy of Continuing Professional Education, Rheumatology, Moscow, Russian Federation

Background: The concept of treat to target (T2T) in psoriatic arthritis (PsA) has been established recently and already shown its benefits [1]. But the long-term outcomes of the T2T have not been studied yet.

Objectives: To study 5 years (yrs) follow-up of PsA patients (pts) treated according to T2T strategy at the early stage.

Methods: 35 (M/F-17/18) PsA pts fulfilling CASPAR criteria, who were treated according to T2T strategy at the early stage (PsA duration $\leq 2$ yrs) within 24 months (mos) were analyzed. At the time of evaluation mean age is $42.7 \pm 11.2$ yrs, median (Me) PsA duration 72 [60;95] mos, psoriasis duration 120 [88;180] mos. All pts underwent standard clinical examinations of PsA before started T2T therapy and at follow-up. Within 24 mos of T2T strategy all pts were taking Methotrexate (MTX) monotherapy in increasing dose up to $25 \mathrm{mg} / \mathrm{wk}$ and 18 out of 35 (51\%) pts received MTX in combination with iTNF. When T2T study was stopped all pts were treated according to standard care with NSAIDs, bDMARDs, MTX, tsDMARDs based on PsA activity and physician decision. The number of pts achieved minimal disease activity (MDA, 5 of 7 ) and remission by DAPSA ( $\leq 4)$ / low disease activity (LDA) $\leq 14$ ) at the 24 mos of T2T strategy and at 5 yrs follow-up were calculated. The results are presented in the form of mean values, median, upper and lower quartiles.

Results: Me duration of follow-up is 68 [53.5;81.5] mos. At 24 mos Me DAPSA $3.48[0.45 ; 21.76]$, remission by DAPSA (REM-DAPSA) were seen in 20 out of $35(57 \%)$ pts, LDA-DAPSA in $4(12 \%)$ pts, moderate activity (MoA) by DAPSA in $6(17 \%)$ pts and high disease activity by DAPSA (HDA-DAPSA) in $5(14 \%)$ pts. MDA was noted in 21 out of $35(60 \%)$ pts. At 5 yrs Me DAPSA 7.4 [2.22;13.87], REM-DAPSA was noted in 12 (34\%) pts, LDA-DAPSA in 14 (40\%), MoA-DAPSA in $5(14 \%)$, HDA-DAPSA in $4(12 \%)$ pts. MDA was observed in 17 of 35 pts $(49 \%)$. Among 20 pts who had REM-DAPSA at 24 mos only 6 pts $(30 \%)$ remained in remission at 5 yrs follow-up and 12 out of 21 pts $(57.14 \%)$ remained in MDA status.

Conclusion: In early PsA pts remission and MDA are achievable goal of T2T strategy. But most pts lost remission/MDA after this strategy was changed to a standard care, despite being in remission/MDA status before change of therapy. Further investigations of the long-term outcomes of T2T strategy in PsA, including radiographic outcomes are needed.

REFERENCES:

[1] Coates LC, Moverley AR, McParland L, et al. Lancet 2015; 386: 2489-98.

Disclosure of Interests: None declared.

DOI: 10.1136/annrheumdis-2021-eular.1985

\section{$\mathrm{AB} 0547$ \\ ASSOCIATION BETWEEN ACHIEVEMENT OF LOW DISEASE ACTIVITY OR REMISSION WITH IMPROVEMENT IN QUALITY OF LIFE IN UPADACITINIB-TREATED PATIENTS IN THE PHASE 3 SELECT-PSA 1 AND 2 STUDIES}

A. Kavanaugh ${ }^{1}$, P. J. Mease ${ }^{2}$, K. Douglas ${ }^{3}$, F. Behrens ${ }^{4}$, D. Haaland ${ }^{5}$,

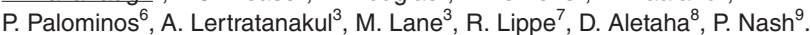
${ }^{1}$ University of California San Diego, Division of Rheumatology, Allergy and Immunology, San Diego, California, United States of America; ${ }^{2}$ Swedish Medical Center/Providence St. Joseph Health and University of Washington, Rheumatology, Seattle, Washington, United States of America; ${ }^{3}$ AbbVie Inc., Immunology, North Chicago, United States of America; ${ }^{4}$ Rheumatology and Fraunhofer ITMP - Translational Medicine and Pharmacology, Goethe University, Rheumatology, Frankfurt, Germany; ${ }^{5}$ McMaster University, Hamilton, Ontario and The Waterside Clinic, Rheumatology, Barrie, Ontario, Canada; ${ }^{6} \mathrm{Hospital}$ de Clínicas de Porto Alegre, Rheumatology Service, Porto Alegre, Brazil; ${ }^{7}$ AbbVie Deutschland GmbH \& Co. KG, Immunology, Wiesbaden, Germany; ${ }^{8}$ Medical University of Vienna, Währinger Gürtel, Department of Medicine III, Division of Rheumatology, Vienna, Austria; ${ }^{9}$ Griffith University, Rheumatology Research Unit, Sunshine Coast, Brisbane, Queensland, Australia

Background: The efficacy and safety of upadacitinib (UPA) in patients (pts) with active psoriatic arthritis (PsA) was demonstrated in the phase 3 SELECT-PsA 1 and SELECT-PsA 2 clinical trials. ${ }^{1,2}$

Objectives: To explore the relationship between achievement of low disease activity (LDA) or remission (REM) and pt-reported outcomes (PROs) in SELECTPsA 1 and 2.

Methods: The SELECT-PsA program enrolled pts with prior inadequate response or intolerance to $\geq 1$ non-biologic disease-modifying antirheumatic drug (DMARD; SELECT-PsA 1) or $\geq 1$ biologic DMARD (SELECT-PSA 2). Pts were randomized to 56 weeks (wks) of blinded treatment with UPA 15 or $30 \mathrm{mg}$ once daily (QD), placebo switched to UPA 15 or $30 \mathrm{mg}$ QD at Wk 24, or adalimumab (SELECT-PsA 1 only) $40 \mathrm{mg}$ every other wk. LDA and REM were evaluated using the minimal disease activity (MDA; fulfillment of 5 out of 7) criteria and the Disease Activity index for Psoriatic Arthritis (DAPSA; cutoff $\leq 4$ ), respectively. PROs assessed included Health Assessment Questionnaire-Disability Index (HAQ-DI), 36-Item Short-Form Survey physical component summary (SF-36 PCS), 5-Level EuroQol 5-Dimension (EQ-5D-5L) Index, and EQ-5D-5L Visual Analog Scale (VAS). Integrated data through Wk 56 from SELECT-PsA 1 and 2 from the full analysis set with both continuous UPA $15 \mathrm{mg}$ and $30 \mathrm{mg}$ groups were analyzed by responder status at Wks 24 and 56 . Changes from baseline (BL) in PROs were analyzed using mixed effects repeated measures models (fixed effects for study, current use of non-biologic DMARDs, treatmen group, visit, responder status, and continuous BL PROs). As-observed data were used in the models.

Results: A total of 1281 pts were included in the analysis (UPA $15 \mathrm{mg}, \mathrm{n}=640$; UPA $30 \mathrm{mg}, \mathrm{n}=641$ ). MDA was achieved by $33 \%$ (UPA $15 \mathrm{mg}$ ) and $40 \%$ (UPA $30 \mathrm{mg}$ ) of patients at

Wk 24 , and $40 \%$ (UPA $15 \mathrm{mg}$ ) and $43 \%$ (UPA $30 \mathrm{mg}$ ) at Wk 56; and DAPSA-REM by $10 \%$ (UPA $15 \mathrm{mg}$ ) and $17 \%$ (UPA $30 \mathrm{mg}$ ) at Wk 24, and $16 \%$ (UPA $15 \mathrm{mg}$ ) and $18 \%$ (UPA $30 \mathrm{mg}$ ) at Wk 56. Pts who achieved MDA or DAPSA-REM (responders) at Wk 56 achieved larger reductions in HAQ-DI and larger increases in SF-36 PCS, EQ-5D-5L Index and EQ-5D-5L VAS compared with non-responders (Table 1) (all $p<0.0001$; statistical significance was exploratory in nature). MDA or DAPSA-REM response at Wk 24 was also associated with greater PRO improvements at Wk 56 (Figure 1). Consistent with the results presented for MDA and DAPSA-REM, patients who achieved Very Low Disease Activity or DAPSA-LDA also experienced greater improvements in PROs than those who did not.

Table 1. Change from BL in PROs at Wk 56 by MDA and DAPSA-REM responder status at Wk 56

\begin{tabular}{|c|c|c|c|c|}
\hline \multirow[b]{2}{*}{$\begin{array}{l}\text { Least squares mean change } \\
\text { from } \mathrm{BL} \\
(95 \% \mathrm{Cl}) \text {, unless stated otherwise }\end{array}$} & \multicolumn{2}{|c|}{$\begin{array}{l}\text { UPA } 15 \mathrm{mg} \text { QD } \\
(\mathrm{n}=640)\end{array}$} & \multicolumn{2}{|c|}{$\begin{array}{l}\text { UPA } 30 \mathrm{mg} \text { QD } \\
(\mathrm{n}=641)\end{array}$} \\
\hline & $\begin{array}{l}\text { Non- } \\
\text { responder }\end{array}$ & Responder & $\begin{array}{l}\text { Non- } \\
\text { responder }\end{array}$ & Responder \\
\hline $\begin{array}{l}\text { MDA, } n^{a} \\
\text { HAQ-DI }\end{array}$ & $\begin{array}{l}386 \\
-0.26(-0.30\end{array}$ & $\begin{array}{l}254 \\
,-0.61^{*}(-0.66\end{array}$ & $\begin{array}{l}368 \\
-0.27(-0.31\end{array}$ & $\begin{array}{l}273 \\
,-0.69^{*}(-0.74,\end{array}$ \\
\hline SF-36 PCS & $\begin{array}{l}-0.22) \\
5.25(4.60, \\
5.90)\end{array}$ & $\begin{array}{l}-0.56) \\
12.63^{\star}(11.84 \\
13.41)\end{array}$ & $\begin{array}{l}-0.23) \\
5.09(4.42 \\
5.75)\end{array}$ & $\begin{array}{l}-0.64) \\
13.84^{*} \\
(13.08,14.59)\end{array}$ \\
\hline EQ-5D-5L Index & $\begin{array}{l}0.11(0.09 \\
0.12)\end{array}$ & $\begin{array}{l}0.25^{\star}(0.23 \\
0.26)\end{array}$ & $\begin{array}{l}0.10(0.09 \\
0.12)\end{array}$ & $\begin{array}{l}0.27^{\star}(0.25 \\
0.28)\end{array}$ \\
\hline EQ-5D-5L VAS & $9.3(7.8,10.9$ & $\begin{array}{l}23.3^{\star}(21.4 \\
25.1)\end{array}$ & $9.0(7.4,10.5$ & $\begin{array}{l}26.1^{*}(24.4 \\
27.9)\end{array}$ \\
\hline $\begin{array}{l}\text { DAPSA-REM, } n^{a} \\
\text { HAQ-DI }\end{array}$ & $\begin{array}{l}539 \\
-0.36(-0.39\end{array}$ & $\begin{array}{l}101 \\
,-0.63^{\star}\end{array}(-0.71$ & $\begin{array}{l}526 \\
-0.39(-0.43\end{array}$ & $\begin{array}{l}115 \\
3,-0.71^{*}(-0.78,\end{array}$ \\
\hline SF-36 PCS & $\begin{array}{l}-0.32) \\
6.99(6.39 \\
7.59)\end{array}$ & $\begin{array}{l}-0.55) \\
14.54^{\star}(13.22 \\
15.86)\end{array}$ & $\begin{array}{l}-0.35) \\
7.43(6.82 \\
8.03)\end{array}$ & $\begin{array}{l}-0.63) \\
15.16^{\star}(13.91 \\
16.40)\end{array}$ \\
\hline EQ-5D-5L Index & $\begin{array}{l}0.14(0.13, \\
0.15)\end{array}$ & $\begin{array}{l}0.27^{*}(0.24 \\
0.30)\end{array}$ & $\begin{array}{l}0.15(0.14 \\
0.16)\end{array}$ & $\begin{array}{l}0.29^{*}(0.26 \\
0.31)\end{array}$ \\
\hline EQ-5D-5L VAS & $\begin{array}{l}12.7(11.3, \\
14.0)\end{array}$ & $\begin{array}{l}26.7^{\star}(23.7 \\
29.8)\end{array}$ & $\begin{array}{l}13.3(11.9, \\
14.7)\end{array}$ & $\begin{array}{l}30.0^{*}(27.1, \\
32.8)\end{array}$ \\
\hline
\end{tabular}

${ }^{*} p<0.0001$ vs non-responder (statistical significance was exploratory in nature) ${ }^{a} n$ may vary by PRO assessed

Conclusion: Among UPA-treated pts with PsA, improvements in quality of life and physical function were greater in pts who achieved MDA or DAPSA-REM than in those who did not. Despite DAPSA-REM being a more stringent measure (achieved by a smaller proportion of patients), these improvements were similar between MDA and DAPSA-REM responders.

REFERENCES:

[1] Mclnnes I, et al. Ann Rheum Dis 2020;79(Suppl 1):16-7; 2. Mease PJ, et al. Ann Rheum Dis 2020 